\title{
Macrostructural order and optical properties of polyfluorene-based polymer films
}

\author{
Shotaro Hayashi, Shinsuke Inagi and Toshio Fuchigami \\ Polymer Journal (2010) 42, 772-775; doi:10.1038/pj.2010.58; published online 21 July 2010
}

Keywords: excimer; luminescence; ordered structure; poly(fluorene)

\section{INTRODUCTION}

Because $\pi$-conjugated polymers are capable of forming large area films and are compatible with various substrates such as flexible and conformable plastics, there has been much interest in their potential application in semiconductors, organic light emitting diodes, field-effect transistors and photovoltaic cells. ${ }^{1,2}$ Among the $\pi$-conjugated polymers, polyfluorenes $(\mathrm{PFs})^{3}$ and fluorene-based copolymers ${ }^{4,5}$ have been extensively studied because of their exceptional optoelectronic properties. Although the self-assembly of $\pi$-conjugated polymers is known to remarkably influence device performance, ${ }^{6,7}$ few discussions of the correlation between the optical properties and macrostructural order of fluorene-based homo- and copolymers in the film state has been reported. ${ }^{8,9}$ Interpolymer excimer formation of $\pi$-conjugated polymer films is a particularly important factor in device fabrication. ${ }^{10,11}$

To our knowledge, fluorene homopolymers such as poly(9,9-dioctylfluorene), POF, show only slight excimeric properties in the film state, ${ }^{12}$ although alternating copolymers such as poly(9,9-difluorofluorene-alt-9,9-dioctylfluorene), $\mathbf{P}$ (FF-alt-OF), previously prepared in our laboratory (Scheme 1), exhibit characteristic optoelectronic properties such as interpolymer excimer formation in highly concentrated solutions, intramolecular charge transfer and good $n$-type character. $^{13,14}$ Excimer formation in highly concentrated solutions implies that the alternating fluorene-based copolymers promote $\pi-\pi$ stacking and crystallization more efficiently than fluorene homopolymers. In this paper, we report the relationships between macrostructural order and photoluminescent (PL) properties through powder $\mathrm{X}$-ray diffraction and PL analysis. In addition, we also report the PL behavior of polymer blends composed of PFs and poly(methyl methacrylate), PMMA, in the film state.

\section{EXPERIMENTAL PROCEDURE}

Poly(fluorene)s were prepared according to the previous work. ${ }^{13-15}$ PMMA was synthesized by radical polymerization of methylmethacrylate with azobis (isobutyronitrile) in toluene.

Ultraviolet-visible spectra were obtained on a Shimadzu UV-1600 spectrophotometer (Shimadzu, Kyoto, Japan). Infrared spectra were taken on a JASCO FT/IR-410 infrared spectrometer (JASCO, Tokyo, Japan) by casting the sample from a chloroform solution on a $\mathrm{NaCl}$ plate. Cyclic voltammetry measurements were recorded on an ALS 600A Electrochemical Analyzer (CH Instruments, Inc., Austin, TX, USA). X-ray diffraction patterns were recorded on a RIGAKU RINT2100 Ultima+/PC X-ray diffractometer (RIGAKU, Tokyo, Japan). For the electroluminescent (EL) experiment, poly(3,4-ethylenedioxythiophene) doped with poly(styrenesulfonate), as the hole-injection-transport layer, was introduced between emissive layer and indium tin oxide glass substrate cleaned by successive ultrasonic treatments. The solution of the poly(3,4-ethylenedioxythiophene)/poly(styrenesulfonate) in aqueous isopropyl alcohol was spincoated on the surface-treated indium tin oxide substrate and dried on a hot plate for $30 \mathrm{~min}$ at $110^{\circ} \mathrm{C}$. On top of the poly(3,4-ethylenedioxythiophene)/ poly(styrenesulfonate) layer, the emissive polymer film was obtained by spin casting toluene solution of the polymer. The emissive polymer thin film prepared had a uniform surface with a thickness of around $30 \mathrm{~nm}$. The emissive film was dried in vacuum, and 1,3,5-tri(phenyl-2-benzimidazole)-benzene $(10 \mathrm{~nm})$, barium $(3 \mathrm{~nm})$, aluminum $(100 \mathrm{~nm})$ were deposited on the top of the polymer films through a mask by vacuum evaporation at pressures below $10^{-7} \mathrm{~mm} \mathrm{Hg}$, yielding active areas of $4 \mathrm{~mm}^{2}$. For the determination of the device characteristics, current density-voltage $(J-V)$ and luminance-voltage $(L-V)$ characteristics of the device was measured with a Minolta CS-1000 spectroradiometer (Minolta, Tokyo, Japan) and with a Minolta LS-110 luminance meter (Minolta). A Keithley 2400 source meter (Keithley, Cleveland, OH, USA) connected to a microcomputer (Epson Direct, Nagano, Japan) was used to operate the devices.

\section{RESULTS AND DISCUSSION}

To explore the relationship between structural character and optical properties of PFs, POF $\left(M_{\mathrm{n}}=13400, M_{\mathrm{w}}=21900, M_{\mathrm{w}} / M_{\mathrm{n}}=1.64\right)$, and poly(fluorene-alt-9,9-dioctylfluorene), $\mathbf{P}(\mathrm{HF}-$ alt-OF $) \quad\left(M_{\mathrm{n}}=2900\right.$, $\left.M_{\mathrm{w}}=3800, M_{\mathrm{w}} / M_{\mathrm{n}}=1.30\right)$ were synthesized by the Suzuki-Miyaura coupling polymerization $\left(100^{\circ} \mathrm{C}, 48 \mathrm{~h}\right)$ of 9,9-dioctylfluorene2,7-diboronic acid ester and 9,9-dioctyl-2,7-dibromofluorene or 2,7-dibromofluorene with tetrakis(triphenylphosphine)palladium as a catalyst in a toluene $/ 2 \mathrm{M}$ potassium carbonate solution (Scheme 1). ${ }^{15}$ P(HF-alt-OF $)\left(M_{\mathrm{n}}=5800, M_{\mathrm{w}}=18300, M_{\mathrm{w}} / M_{\mathrm{n}}=3.16\right)$ was synthesized using the procedure reported previously (Scheme 1). ${ }^{13,14}$

The PL spectra of POF, P(HF-alt-OF) and P(FF-alt-OF) in chloroform solutions showed emission peaks at 416,422 and $409 \mathrm{~nm}$, respectively (Figure 1, solid line). The PL spectra in the film state 

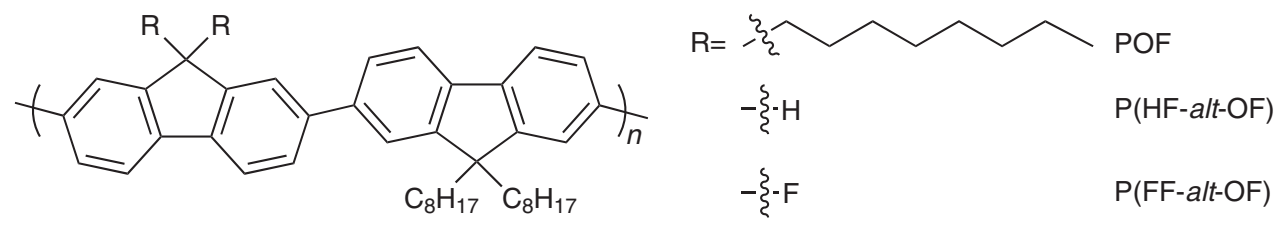

Scheme 1 Poly(fluorenes).

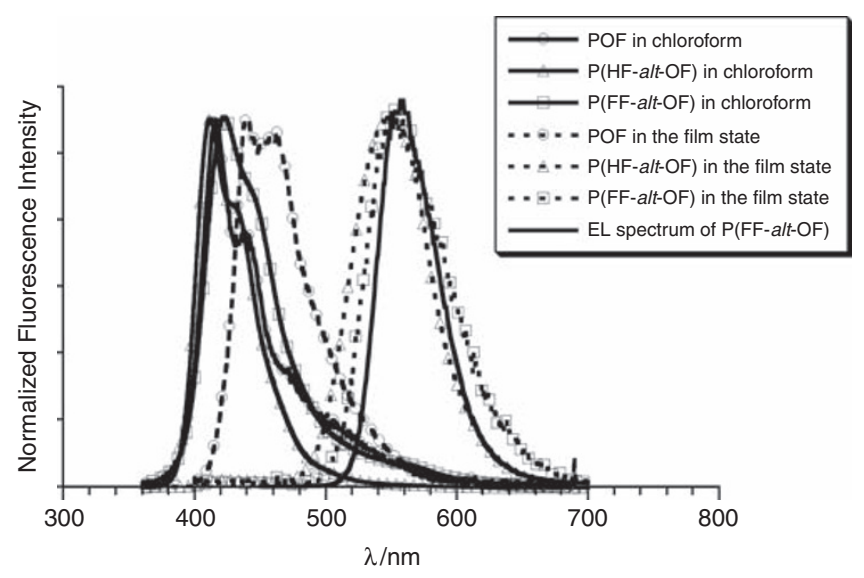

Figure $1 \mathrm{PL}$ spectra of $\mathrm{POF}, \mathrm{P}(\mathrm{HF}-a$ alt-OF) and $\mathrm{P}(\mathrm{FF}$-alt-OF) in a dilute chloroform solution and in the film state, and EL spectrum of P(FF-alt-OF).

were measured using a polymer thin film coated on a glass plate by spin casting. The slightly red shifted spectrum of POF in the film state compared with that in chloroform solution indicates minimal excimeric formation because of the steric hindrance of the dense dioctyl groups (Figure 1). The spectra of $\mathbf{P}(\mathbf{H F}-$ alt-OF $)$ and $\mathbf{P}(\mathbf{F F}-$ alt-OF) in the film state showed emission peaks at 538 and $545 \mathrm{~nm}$, respectively (Figure 1, dotted line), which are highly red shifted from those seen in chloroform solution. The large Stoke's shifts observed in the spectra of the alternating copolymers are derived from large structural differences in the polymers when in solution versus the film state. The single peaks for both alternating copolymers in the film state indicate the formation of perfect interpolymer excimers. ${ }^{10,11}$

To exploit the perfect excimeric property of these polymers in the film state, an EL device was fabricated from $\mathbf{P}(\mathbf{F F}-$ alt $-\mathbf{O F})$ with the following structure: indium tin oxide anode, poly(3,4-ethylenedioxythiophene)/poly(styrenesulfonate) hole-injection layer $(30 \mathrm{~nm})$, $\mathbf{P}$ (FF-alt-OF) (30 nm), 1,3,5-tris( $N$-phenylbenzimidazol-2-yl)benzene electron transporting layer $(10 \mathrm{~nm})$, barium $(3 \mathrm{~nm})$ and aluminum $(100 \mathrm{~nm})$ as a cathode. A unimodal electroluminescence was observed with a narrow emission band at $550 \mathrm{~nm}\left(7.1 \mathrm{~cd} \mathrm{~m}^{-2}\right.$ at $8.5 \mathrm{~V}$, $0.0048 \mathrm{~cd} \mathrm{~A}^{-1}$ at a brightness of $5.0 \mathrm{~mA} \mathrm{~cm}^{-2}$ ) as seen in Figure 1 . The emission peak was in good agreement with the previous photoluminescence measurement. These results confirm that an excimer EL device can be easily prepared using simple PF alternating copolymers as the luminescence layer.

The macrostructural order of the fluorene-based homo- and alternating copolymer thin films were assayed by $\theta-2 \theta$ X-ray diffraction scans of drop-cast films. ${ }^{16}$ As shown in Figure 2, the alternating copolymers $\mathbf{P}$ (HF-alt-OF) and $\mathbf{P}(\mathbf{F F}-$ alt-OF) exhibit crystalline patterns with distinct diffraction peaks, whereas homopolymer POF exhibits a non-crystalline (amorphous) profile. The strong peaks for the copolymers were observed at $2 \theta=6.94^{\circ}$ and $6.12^{\circ}$, which correspond to $d$-spacings of 12.72 and $14.43 \AA$ and are in good agreement

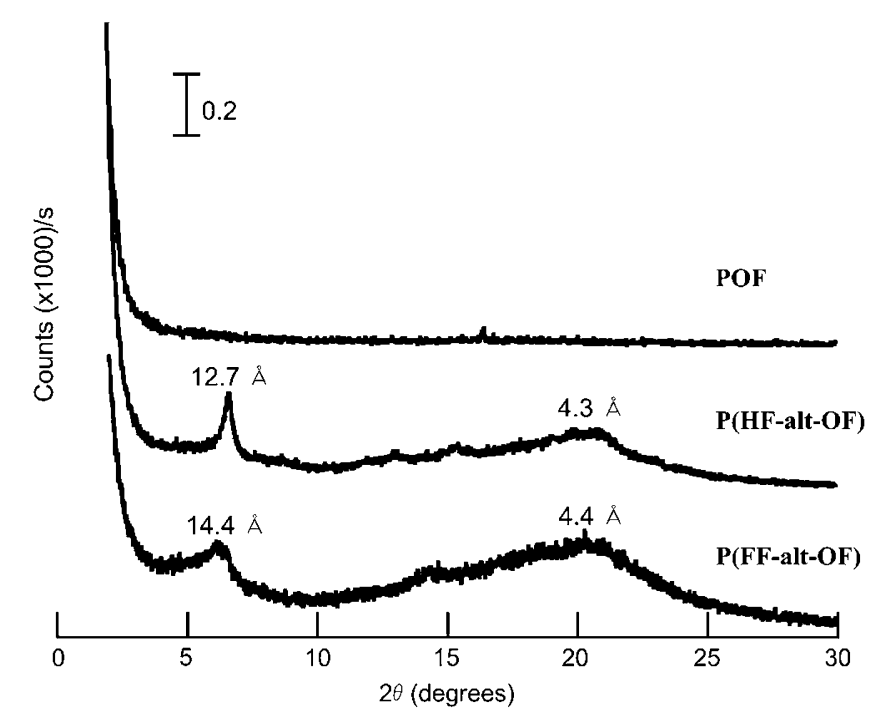

Figure 2 Powder X-ray diffraction patterns of POF, P(HF-alt-OF) and P(FF-alt-OF).

with the length of the bulky dioctyl groups that are oriented perpendicular to the main chain of the polymer. These results suggest that the alternating PFs $\mathbf{P}(\mathbf{H F}-$ alt-OF $)$ and $\mathbf{P}(\mathbf{F F}-$ alt-OF $)$ have a lamellar patterned $d$-spacing (Figure 3 ). The strong broad peaks for the copolymers at ca. $2 \theta=20^{\circ}$ correspond to $\pi-\pi$ stacking distances of 4.2-4.4 $\AA$ and are similar to the distances measured previously in other fluorene-based polymeric and oligomeric semiconductors. ${ }^{17,18}$ The existence of such peaks indicates an interdigitation packing mode as depicted in Figure 3. The formation of this characteristic packing mode, which produces perfect interpolymer excimeric fluorescence, is likely due to the presence of alternating small and large (bulky) side chains on the PFs.

We proposed that with such a structure, by blending additives into the film, it could be possible to interrupt the lamellar packing of the copolymers and disrupt the $\pi-\pi$ stacking, thus quenching the excimeric photoluminescence. The use of polymer blending to control the optical properties and morphologies of $\pi$-conjugated polymers has been reported. ${ }^{19,20}$ To study the relationship between the macrostructural order $(\pi-\pi$ stacking) and excimeric properties of $\mathbf{P}(\mathbf{H F}-$ alt-OF $)$ and $\mathbf{P}(\mathrm{FF}-$ alt $-\mathrm{OF})$ copolymers, PL measurements for films of various PF/PMMA blends were taken (Figure 4). At different ratios, P(HF-altOF) and $\mathbf{P}(\mathbf{F F}-$ alt-OF) show two PL emission peaks at 408, 538 and $403,545 \mathrm{~nm}$, respectively (Figure 4). Quenching of the emissions at 538 and $545 \mathrm{~nm}$ was observed to increase with increasing PMMA content due to disruption of $\pi-\pi$ stacking by the PMMA segments. At the same time, with increasing PMMA content the PL peaks for nonaggregated PFs at 408 and $403 \mathrm{~nm}$ increased. The film containing $1.0 \mathrm{wt} \% \mathbf{P}(\mathbf{F F}-$ alt-OF $)$ showed a pale blue fluorescence similar to that observed for PF in a highly dilute solution. 


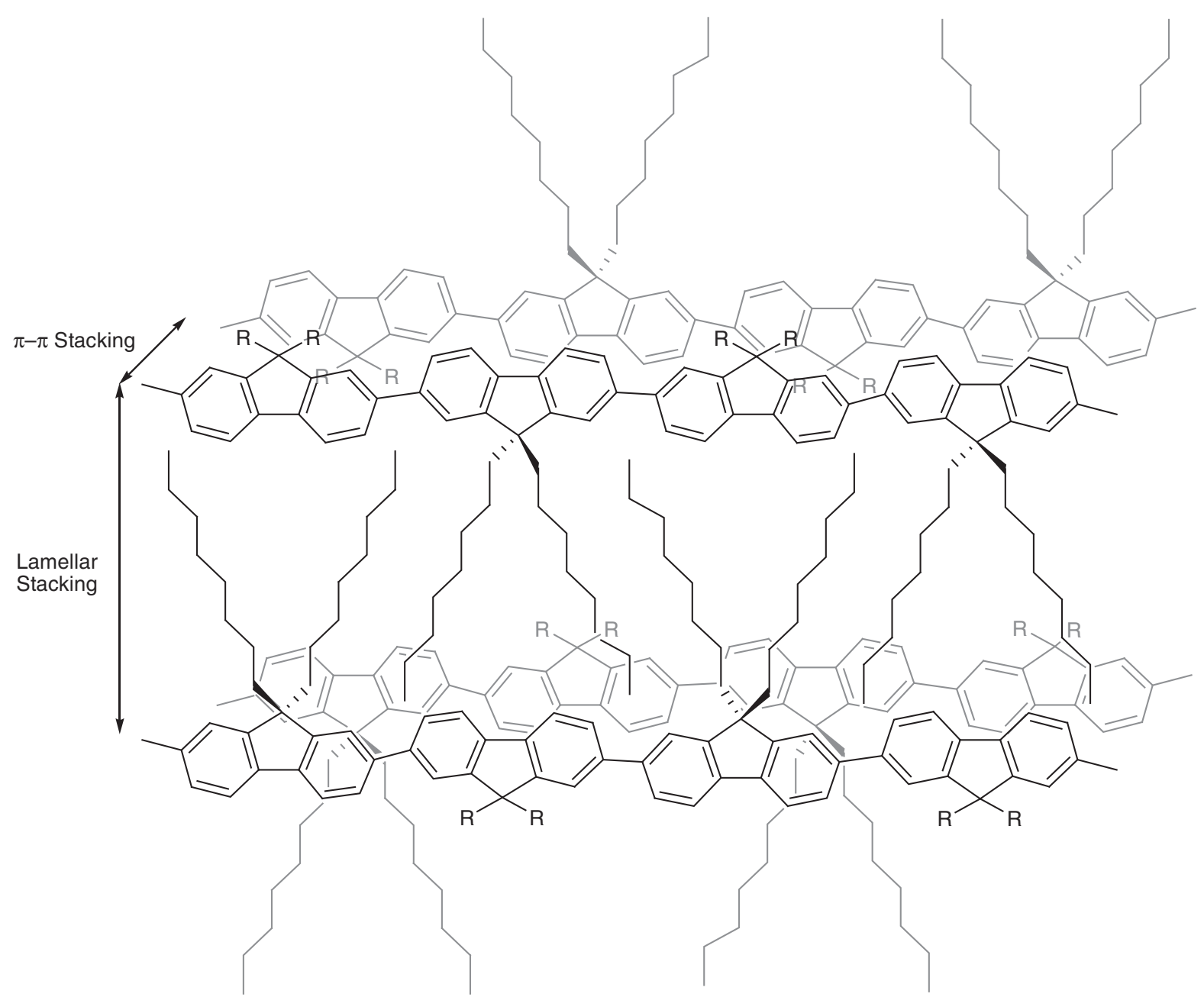

Figure 3 Schematic diagram of the two-dimensional interdigitation packing structure for alternating fluorine copolymers with interchain $d$-spacing.
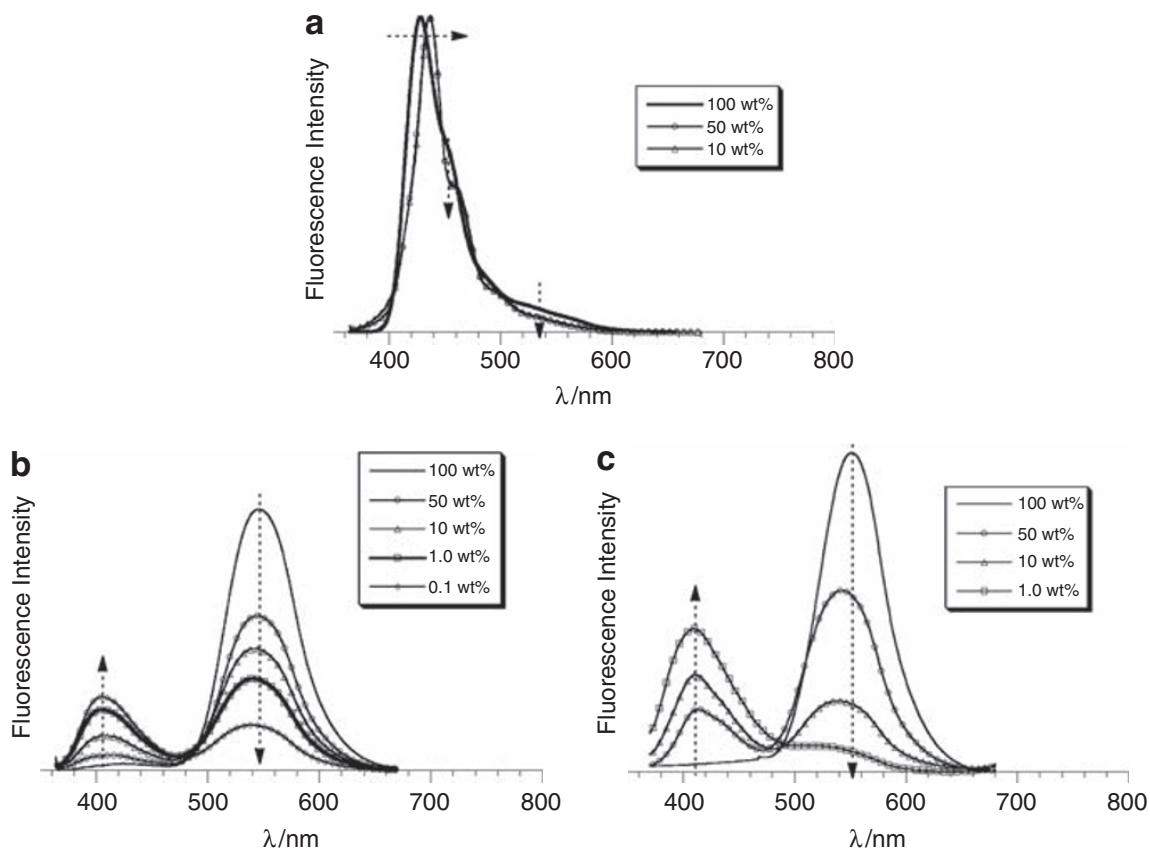

Figure 4 PL spectra of (a) POF, (b) P(HF-alt-OF) and (c) P(FF-alt-OF) in the film state at various PFs/PMMA blend ratio. 


\section{CONCLUSION}

In conclusion, fluorene-based alternating copolymers are considered to assume an ordered macrostructure involving lamellar and $\pi-\pi$ stacking in the film state. The ordered structure gives rise to perfect interpolymer excimeric luminescence, which can be used as a luminescence layer in an EL device. Furthermore, a gradual quenching of excimeric fluorescence and increase in the intensity of non-aggregated fluorescence for alternating copolymers in the film state occurs when blending PMMA into the polymer film. We successfully demonstrated to control the degree of macrostructural order and emission properties of $\pi$-conjugated polymer films.

\section{ACKNOWLEDGEMENTS}

We thank Prof Shizuo Tokito for preparation of the electroluminescence device and EL measurements. This study was supported by a Grant-in-Aid for Scientific Research (no. 17073008) in the Priority Area 'Science of Ionic liquids' (Area Number 452), a Grant-in-Aid for Scientific Research (B) (no. 20350071) and a Grant-in-Aid for Young Scientists (Start-up) (no. 20850015).

1 Chang, T., Yang, S. \& Hsu, C. Synthesis of conjugated polymers for organic solar cell applications. Chem. Rev. 109, 5868-5923 (2009).

2 Grimsdale, A. C., Chan, K. L., Martin, R. E., Jokisz, P. G. \& Holmes, A. G. Synthesis of light-emitting conjugated polymers for applications in electroluminescent devices. Chem. Rev. 109, 897-1091 (2009).

3 Hand book of Conducting Polymer Second Edition Revices and Expanded. Skotheim, T. A., Elsenbaumer, R. L., \& Reynolds, J. R. (eds). Marcel Dekker Inc.: New York, 1998.

4 Pal, B., Yen, W., Yang, J \& Su, W. Substituent effect on the optoelectronic properties of alternating fluorene-thiophene copolymers. Macromoloecules 40, 8189-8194 (2007).

5 Inagi, S., Hayashi, S., Hosaka, K. \& Fuchigami, T. Facile functionalization of a thiophenefluorene alternating copolymer via electrochemical polymer reaction. Macromolecules 42, 3881-3883 (2009).

6 Coffin, R. C., Peet, J., Rogers, J. \& Bazan, G. C. Streamlined microwave-assisted preparation of narrow-bandgap conjugated polymers for high-performance bulk heterojunction solar cells. Nat. Chem. 1, 657-661 (2009).
7 Zhang, Y., Tajima, K., Hirota, K. \& Hashimoto, K. Synthesis of all-conjugated diblock copolymers by quasi-living polymerization and observation of their microphase separation. J. Am. Chem. Soc. 130, 7812-7813 (2008).

8 Rothe, C., Galbrecht, F., Scherf, U. \& Monkman, A. The $\beta$-phase of poly(9,9-dioctylfluorene) as a potential system for electrically pumped organic lasing. Adv. Mater. 18, 2137-2140 (2006).

9 Grell, M., Bradley, D. D. C., Ungar, G., Hill, J. \& Whitehead, K. S. Interplay of physical structure and photophysics for a liquid crystalline polyfluorene. Macromolecules 32, 5810-5817 (1999).

10 Jenekhe, S. A. \& Osaheni, J. S. Excimers and exciplexes of conjugated polymers. Science 265, 765-768 (1994).

$11 \mathrm{Kim}$, Y., Bouffard, J., Kooi, S. E. \& Swager, T. M. Highly emissive conjugated polymer excimers. J. Am. Chem. Soc. 127, 13726-13731 (2005).

12 Kwon, Y. K., Kim, H. S., Kim, H. J., Oh, J. H., Park, H. S., Ko, Y. S., Kim, K. B. \& Kim, M. S. Reduced excimer formation in polyfluorenes by introducing coil-like poly[penta(ethylene glycol) methyl ether methacrylate] block segments. Macromolecules 42, 887-891 (2009).

13 Inagi, S., Hayashi, S. \& Fuchigami, T. Electrochemical polymer reaction: selective fluorination of a poly(fluorene) derivative. Chem. Commun. 1718-1720 (2009).

14 Hayashi, S., Inagi, S. \& Fuchigami, T. Synthesis of 9-substituted fluorene copolymers via chemical and electrochemical polymer reaction and their optoelectronic properties. Macromolecules 42, 3755-3760 (2009).

15 Kameshima, H., Nemoto, N. \& Endo, T. Synthesis and properties of fluorene-based fluorinated polymers. J. Polym, Sci., Part A: Polym. Chem. 39, 3143-3150 (2001).

16 Yasuda, T., Imase, T., Sakai, S. \& Yamamoto, T. Synthesis, solid structure, and optical properties of new thiophene-based alternating $\pi$-conjugated copolymers containing 4 alkyl-1,2,4-triazole or 1,3,4-thiadiazole unit as the partner unit. Macromolecules 38, 1500-1503 (2005).

17 Lim, E., Jung, B. J., Lee, J., Shim, H. K., Lee, J. I., Yang, Y. S. \& Do, L. M. Thin-film morphologies and solution-processable field-effect transistor behavior of a fluorenethieno[3,2-b]thiophene-based conjugated copolymer. Macromolecules 38, 4531-4535 (2005).

18 Wu, Y., Li, Y., Gardner, S. \& Ong, B. S. J. Indolo[3,2-b]carbazole-based thin-film transistors with high mobility and stability. J. Am. Chem. Soc. 127, 614-618 (2005).

19 Knaapila, M., Vaughan, H. L., Hase, T. P. A., Evans, R. C., Stepanyan, R., Torkkeli, M., Burrows, H. D., Scherf, U. \& Monkman, A. P. Concentration effect on the oriented microstructure in tensile drawn polyfluorenepolyethylene blend. Macromolecules 43, 299-305 (2010).

20 Vamvounis, G., Schulz, G. L. \& Holdcroft, S. Enhanced blue-violet emission from poly(fluorene-co-thiophene) hostguest systems. Macromolecules 37, 8897-8902 (2004). 